\title{
Novel brd4 inhibitors with a unique scaffold exhibit antitumor effects
}

\author{
YOUNG HUN KIM ${ }^{1 *}$, MINSUNG KIM $^{1,2^{*}}$, JI EUN KIM ${ }^{1}$, MIYOUN YOO $^{1}$, HEUNG KYOUNG LEE $^{1}$, \\ CHONG OCK LEE ${ }^{1}$, MINJIN YOO ${ }^{1,3}$, KWAN-YOUNG JUNG ${ }^{1,3}$, YEONGRIN KIM ${ }^{1,3}$, \\ SANG UN CHOI ${ }^{1}$ and $\mathrm{CHI}$ HOON PARK ${ }^{1,3}$ \\ ${ }^{1}$ Bio and Drug Discovery Division, Korea Research Institute of Chemical Technology, Daejeon 34114; \\ ${ }^{2}$ School of Pharmacy, Sungkyunkwan University, Suwon, Kyunggi-do 16419; \\ ${ }^{3}$ Department of Medicinal Chemistry and Pharmacology, \\ Korea University of Science and Technology, Daejeon 34113, Republic of Korea
}

Received August 10, 2020; Accepted January 18, 2021

DOI: $10.3892 / \mathrm{ol} .2021 .12734$

\begin{abstract}
Since bromodomain containing 4 (brd4) has been considered as a prominent cancer target, numerous attempts have been made to develop potent brd4 bromodomain inhibitors. The present study provided a novel chemical scaffold which inhibited brd4 activity. Mid-throughput screening against brd4 bromodomain was performed using alpha-screen and homogeneous time-resolved fluorescence assays. Furthermore, cell cytotoxicity and xenograft assays were performed to examine if the compound was effective both in vitro and in vivo. As a result, it was revealed that compounds having naphthalene-1,4-dione scaffold inhibited the binding of bromodomain to acetylated histone. The compounds with naphthalene-1,4-dione had cytotoxic effects against the Ty82 cell line, a NUT midline carcinoma cell line, whose proliferation is dependent on brd4 activity. A10, one of the compounds with naphthalene-1,4-dione scaffold, also exhibited tumor growth inhibition effects in the xenograft assay. In addition, the compounds exhibited cytotoxic effects against gastric cancer cell lines which were resistant to I-BET-762, a BET bromodomain inhibitor. In conclusion, the novel scaffold to suppress brd4 activity was effective against cancer cells both in vitro and in vivo.
\end{abstract}

\section{Introduction}

In epigenetics, lysine acetylation has been considered as a key step of post-translational modifications $(1,2)$. Histone

Correspondence to: Dr Chi Hoon Park, Bio and Drug Discovery Division, Korea Research Institute of Chemical Technology, Building E4, 141 Gajeong-ro, Daejeon 34114, Republic of Korea E-mail: chpark@krict.re.kr

*Contributed equally

Key words: bromodomain inhibitor, novel scaffold, anticancer agent, mid-throughput screening, brd4 acetyltransferases (HATs) and histone deacetylases (HDACs) functions as 'writers' and 'erasers' respectively by controlling acetyl mark of histone lysine residue (3). For this acetylation to be involved in gene expression, we need a 'reader' to recognize acetylated histone. Bromodomain is one of the best known modules to recognize and bind to acetylated histones (4). In 1992, bromodomain, a protein module containing approximately 110 amino acids, was identified as a lysine acetylation reader in Drosophila melanogaster study (5). In the human genome, there are 46 bromodomain-containing proteins, many of which are HATs, HAT-associated proteins, helicases, ATP-dependent chromatin remodeling complexes, transcriptional coactivators, and nuclear scaffolding proteins. Among them, brd4, one of the BET (bromodmain and extra-terminal proteins) proteins, was revealed to play a crucial role in NUT midline carcinoma (NMC) (6). In the majority of NMC patients,

NUT gene, which is located on chromosome 15q14, is fused with BRD4 or BRD3, creating BRD4-NUT fusion proteins. As knockdown of BRD4-NUT in NMC caused significant decrease in BRD4-NUT positive cell proliferation (7), brd4 has been highlighted as a powerful therapeutic target for NMC. In addition, brd4 knockdown in AML cell lines causes downregulation of c-myc expression as to induce cell death (8). Subsequent studies demonstrated that most of the leukemic and lymphoma cells die by brd4 inhibition (9). For this reason, many studies have been conducted to develop potent bromodomain inhibitors (10). At present, approximately 40 papers relevant to BET inhibitors have been published, and 16 inhibitors are on-going in clinical trial.

Here, we performed mid-throughput screening to discover a new brd4 bromodomain inhibitor. We setup two biochemical assays, alpha-screen and Homogeneous Time Resolved Fluorescence (HTRF), we got hit compound which exhibits excellent efficacy in vitro and in vivo assay.

\section{Materials and methods}

Cell culture. Ty82, and MKN7 cell lines were obtained from JCRB cell bank (Japan). SNU638, SNU719, SNU668, SNU216, 
MKN45, MKN74 and MKN1 cell lines were obtained from Korean cell line Bank (Korea). All cell lines were cultured with RPMI-1640 supplemented with 10\% fetal bovine serum.

Molecular cloning and protein expression, and purification. Brd4 cDNA was provided by Dr. Stefan Knapp from the University of Oxford. N-terminal GST-tagged and C-terminal His-tagged BD1 (GST-BD1-His 6 ) was expressed in E.coli and purified. BD1 spans 47-170 amino acids. The pGEX 6P-1 vector was digested with EcoRI and XhoI restriction enzymes. BD1 PCR was performed with the BD1_Forward primer (5'-ATC TAG GAA TTC CCC CCA GAG ACC TCC AAC CC-3') and BD1_Rev primer (5'-ATC TAG CTC GAG TTA GTG GTG GTG GTG GTG GTG TTC GAG TGC GGC CGC AAG CTC GGT TTC TTC TGT GGG TA-3'). BL21 Star (DE3) was transformed and induced by $0.1 \mathrm{mM}$ IPTG overnight at $18^{\circ} \mathrm{C}$. The cells were lysed with lysozyme $(1 \mathrm{mg} / \mathrm{ml})$ and sonicated in lysis buffer $\left(50 \mathrm{mM} \mathrm{NaH} \mathrm{PO}_{4}, 300 \mathrm{mM} \mathrm{NaCl}, 10 \mathrm{mM}\right.$ imidazole, and adjusted $\mathrm{pH}$ to 8.0 by $\mathrm{NaOH}$ ) and centrifuged at $8,000 \mathrm{rpm}$ for $30 \mathrm{~min}$. The supernatant was incubated with Ni-NTA beads (Qiagen) for $2 \mathrm{~h}$ at $4^{\circ} \mathrm{C}$ and proteins were eluted with elution buffer $\left(50 \mathrm{mM} \mathrm{NaH}_{2} \mathrm{PO}_{4}, 300 \mathrm{mM} \mathrm{NaCl}, 250 \mathrm{mM}\right.$ imidazole, and adjusted $\mathrm{pH}$ to 8.0 by $\mathrm{NaOH}$ ). Purified His-tag proteins were further purified by size exclusion chromatography on a superdex 16/600 Hiload column (GE Healthcare) using buffer (50 mM Tris- $\mathrm{HCl} \mathrm{pH} \mathrm{7.4,} 200 \mathrm{mM} \mathrm{NaCl})$

Alpha-screen biochemical assay. The alpha-screen assay was performed in accordance with the manufacturer's protocol (PerkinElmer), by using a buffer (50 mM HEPES, $100 \mathrm{mM}$ $\mathrm{NaCl}, 0.1 \%$ BSA, pH 7.4 supplemented with $0.05 \%$ CHAPS) and OptiPlate ${ }^{\mathrm{TM}}-384$ plate (PerkinElmer). Briefly, $2.5 \mu \mathrm{l}$ of compound solution and $5 \mu \mathrm{l}$ of peptide solution [SGRGK(Ac) GGK(Ac)GLGK(Ac)GGAK(Ac)RHRK-biotin] were added to $5 \mu$ l of glutathione-S-transferase (GST) and His-tagged BD1 in OptiPlate ${ }^{\mathrm{TM}}-384$ plate. Streptavidin-coated donor beads and anti-GST alpha-screen acceptor beads were added under low-light condition. Plate was incubated at $25^{\circ} \mathrm{C}$ for 60 min using a Thermomixer C (Eppendorf), and read using a Fusion-Alpha ${ }^{\mathrm{TM}}$ Multilabel Reader (PerkinElmer). The alpha-screen results were confirmed by using alpha-screen TruHit kits (PerkinElmer).

HTRF assay. The HTRF assay was performed in 384-well black polystyrene plate, flat bottom, low flange, non-binding surface (Corning) in assay buffer [50 mM HEPES ( $\mathrm{pH} 7.0$ ), $\mathrm{NaN}_{3} 0.02 \%, 0.01 \%$ BSA, Orthovanadate $\left.0.1 \mathrm{mM}\right] .0 .5 \mu \mathrm{M}$ glutathione-S-transferase (GST) and His-tagged BD1 was co-incubated with $0.2 \mu \mathrm{M}$ of Acetylated peptide and compounds. After $30 \mathrm{~min}$ incubation at $25^{\circ} \mathrm{C}$, Streptavidine-XL665 and anti-GST-Tb was added to the reaction and incubated at $25^{\circ} \mathrm{C}$ for $60 \mathrm{~min}$. The signal was monitored using a microplate reader (Envision; Perkin-Elmer) using excitation at $337 \mathrm{~nm}$ and dual emission at 665 and $620 \mathrm{~nm}$, respectively.

Western blotting. For immunoblotting, cells were washed in PBS, lysed in $1 \mathrm{X}$ sample buffer $(50 \mathrm{mmol} / \mathrm{l}$ Tris- $\mathrm{HCl}$ ( $\mathrm{pH} 6.8)$, $10 \%$ glycerol, $2 \%$ SDS, and 3\% $\beta$-mercaptoethanol), and boiled for $10 \mathrm{~min}$. Lysates were subjected to SDS-PAGE followed by blotting with the indicated antibodies and detection by western blotting substrate ECL reagent (Thermo Fisher Scientific, Inc.). Images were produced using a SensiQ-2000 and Image software. The following antibodies were obtained from Cell Signaling Technology: c-Myc (cat. no. 5605). Tubulin antibody (cat. no. T6199) was purchased from Sigma-Aldrich; Merck KGaA. HRP-conjugated anti-mouse (cat. no. NCI1430KR), and HRP-conjugated anti-rabbit (cat. no. NCI1460KR) antibodies were obtained from Thermo Fisher Scientific, Inc.

Cell cytotoxic assay. For the viability experiments, cells were seeded in 96-well plates at 30\% confluency and exposed to chemicals the next day. After $72 \mathrm{~h}$, WST-1 reagent was added, and absorbance at $450 \mathrm{~nm}$ was measured by using a SpectraMax spectrophotometer (Molecular Devices) in accordance with the manufacturer's instructions. The $\mathrm{IC}_{50}$ values were calculated by using GraphPad Prism version 5 for Windows. The curves were fitted using a nonlinear regression model with a log (inhibitor) versus response formula.

In vivo xenograft. Female athymic $\mathrm{BALB} / \mathrm{c}(\mathrm{nu} / \mathrm{nu})$ mice (6 weeks old) were obtained from Charles River of Japan. Animals were maintained under clean room conditions in sterile filter top cages and housed on high efficiency particulate air-filtered ventilated racks. Animals received sterile rodent chow and water ad libitum. Nude mice were obtained from Charles River of Japan. Mice were euthanized by usage of $\mathrm{CO}_{2}$. The $\mathrm{CO}_{2}$ flow rate for euthanasia was $10-30 \%$ of the cage volume per minute. Ethics approval for Animal experiments were obtained from the Laboratory Animal Care and Use Committee of Korea Research Institute of Chemical Technology. (2018-6C-10-02) Ty82 cells (5x10 ${ }^{6}$ in $100 \mu 1$ were implanted subcutaneously (s.c.) into the right flank region of each mouse and allowed to grow to the designated size. Once tumors reached an average volume of $200 \mathrm{~mm}^{3}$, mice were randomized and dosed via oral gavage daily with the indicated doses of compounds for 14 days. Mice were treated with vehicle, HIT-A, or A10 compound. The number of mice in each group was 6 . Mice were observed daily throughout the treatment period for signs of morbidity/mortality. Tumors were measured twice weekly using calipers, and volume was calculated using the formula: length $\mathrm{x}$ width ${ }^{2} \mathrm{x} 0.5$. Body weight was also assessed twice weekly.

Statistical analysis. Data are presented as the mean \pm standard error in 6 mice for each group. Statistical analysis was conducted using Graphpad Prism 6 software (GraphPad Software). Statistical comparisons between vehicle-treated and compound-treated groups were performed using two-way ANOVA with Dunnett's multiple comparisons test. $\mathrm{P} \leq 0.01$ was considered to indicate a statistically significant difference $(n=6)$. The statistical analysis used in an experiment is described in the figure legend.

\section{Results}

Mid-throughput screening using alpha-screen assay. We performed MTS to identify molecules that have inhibitory activity on brd4 bromodomain with the compound library provided by Korea Chemical Bank (Daejeon, South Korea). 
A

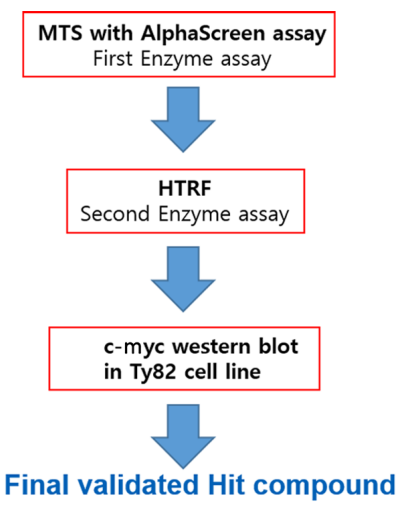

C

\begin{tabular}{cc}
\hline $\begin{array}{c}\text { \% Inhibition at } 17.6 \mu \mathrm{M} \\
\text { in AlphaScreen }\end{array}$ & 98.51 \\
\hline $\mathrm{IC}_{50}$ in alpha-screen & $1.29 \mu \mathrm{M}$ \\
$\mathrm{IC}_{50}$ in HTRF assay & $0.48 \mu \mathrm{M}$ \\
\hline
\end{tabular}

B

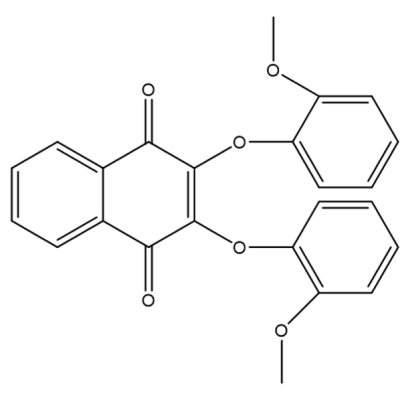

HIT-A

D

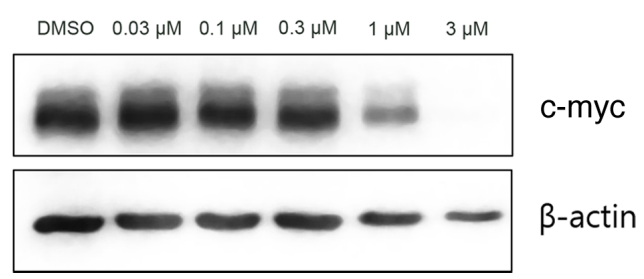

Figure 1. A novel bromodomain inhibitor identified through MTS. (A) Bromodomain inhibitor screening steps in the present study. (B) Structure of HIT-A, which exhibits the efficient inhibitory effect, identified in mid-throughput screening. (C) Inhibitory activity of HIT-A in in vitro biochemical assays, including an alpha-screen assay and ELISA. (D) Ty-82 cells were treated with HIT-A for $18 \mathrm{~h}$, and cell lysates were collected for western blotting to see c-myc level. MTS, mid-throughput screening; HTRF, homogeneous time-resolved fluorescence.

We setup 2 different biochemical assays, alpha-screen assay and HTRF. In this study, we regarded the compound hitting only one biochemical assay as false positive, and the compound hitting both biochemical assays as true hit. The workflow of MTS is shown in Fig. 1A. As a result, we found 1 compound, called as HIT-A, showing inhibition in both biochemical assays (Fig. 1B). The $\mathrm{IC}_{50}$ of HIT-A is $1.29 \mu \mathrm{M}$ in alpha-screen assay, and $0.48 \mu \mathrm{M}$ in HTRF assay (Fig. 1C).

c-myc is known to be highly controlled by brd4 activity, so we checked the c-myc level after compound treatment to judge whether our hit compound is effective in cells (8). The cellular c-myc level was decreased by HIT-A in Ty82 cell line (Fig. 1D). These data demonstrate that HIT-A inhibits brd4 activity in biochemical assay and in cellular assay.

Study on HIT-A derivatives. Out of 400K compounds deposited in Korea Chemical Bank, there are 16 compounds similar to HIT-A in structure. We have conducted both biochemical assays and cell cytotoxic assay with all of these compounds. Interestingly, O-linked compounds (A1, A6, HIT-A, A8, A10, A12 and A14) showed inhibition in both biochemical assays, whereas non O-linked compound (A2, A3, A4, A5, A7, A9, A11, A13 and 1701) showed inhibition only in alpha-screen, not in HTRF (Fig. 2). Because NUT midline carcinoma (NMC) cell lines have a NUT-BRD4 fusion protein by chromosome translocation, the proliferations of NMC cell lines are dependent on brd4 activity (7). Ty82 is one of the NMC cell lines, and also has BRD4-NUT fusion protein (11). Cell cytotoxic assay shows that only $\mathrm{O}$-linked compounds exert cytotoxic effect on Ty82 cells. Non O-linked compounds don't exert any cytotoxic effect on Ty82 cells. This means that only O-linked compounds, not non O-linked, are true brd4 bromodomain inhibitor, and non O-linked compounds are false positive.
In vivo xenograft assay using Ty82. To determine whether our hit compounds exhibit tumor growth inhibition, we conducted an in vivo xenograft assay. Ty 82 cells were implanted in nude mice and allowed to grow to $200 \mathrm{~mm} 3$ in size. Subsequently, HIT-A and A10 were administered orally at daily doses of $100 \mathrm{mpk}$. Tumor volumes were measured for 28 days. As shown in Fig. 3, A10 compound effectively inhibited tumor growth. No weight loss was shown in the mice administered with the new bromodomain inhibitors (Fig. 3B). These results suggest that our compound is a potent bromodomain inhibitor with a unique scaffold in vivo.

Inhibitory effect of our compound on gastric cancer cell. Brd4 bromodomain inhibitor is known to suppress the proliferation of hematological cancer cell. However, it is not well known if bromodomain inhibitor is effective in solid tumor such as gastric cancer cell. Here, we performed cytotoxic assay with various gastric cancer cells (Fig. 4). A7, which doesn't inhibit bromodomain and is similar to hit compound in structure, didn't suppress the proliferation of any gastric cancer cell lines tested. I-BET-762 exerts inhibition only on limited cell lines. However, our hit compounds, A10 and HIT-A, show cytotoxic effect on all the gastric cancer cell lines tested.

To see the c-myc protein level, we performed western blotting with the cell lysates treated with compounds (Fig. 5). SNU-638, MNK-45 and Ty82 cells were treated with A10 or I-BET-762. As we expected, c-myc in Ty82 cell line is downregulated by A10. I-BET-762 downregulated the c-myc level in SNU-638 to which I-BET-762 had cytotoxic effect. I-BET-762 did not downregulate the c-myc level of MKN-45 to which I-BET-762 had no cytotoxic effect. Interestingly, although A10 compound had cytotoxic effect to both SNU-638 and MKN-45, it downregulated the c-myc level only in SNU-638. It means that A10 compound has another cytotoxic mechanism other than c-myc signaling in MKN-45. 


\begin{tabular}{|c|c|c|c|c|c|}
\hline Compound & R1 & R2 & $\begin{array}{c}\text { AlphaScreen } \\
(\mu \mathrm{M})\end{array}$ & $\begin{array}{l}\text { HTRF } \\
(\mu \mathrm{M})\end{array}$ & $\begin{array}{l}\text { Cytotoxicity } \\
\text { assay }(\mu \mathrm{M})\end{array}$ \\
\hline $\mathrm{A} 1$ & 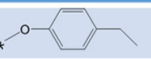 & $* 0\langle\rangle$ & 4.40 & 3.5 & 1.05 \\
\hline $\mathrm{A} 2$ & $x^{4}-1$ & $*^{H-H}-$ & 1.17 & $>20$ & $>20$ \\
\hline A3 & $*^{2}$ & $* \sqrt{0}$ & 2.20 & $>20$ & 12.96 \\
\hline A4 & $*$ - $\mathrm{CH}_{3}$ & ${ }^{*} \mathrm{~S} 工 \mathrm{OH}$ & $>16$ & & $>20$ \\
\hline A5 & $* 0^{\prime}$ & $x^{H}-1-$ & 2.77 & $>20$ & $>20$ \\
\hline A6 & & $\leftarrow^{0-1}$ & 2.65 & 1.41 & 2.22 \\
\hline HIT-A & & & 1.29 & 0.48 & 1.59 \\
\hline A7 & $*$ - $0^{\prime}$ & $x^{H}$ & $>16$ & & $>20$ \\
\hline A8 & $\times 0$ & $x^{\circ}$ & 3.18 & 1.33 & 0.74 \\
\hline A9 & * & i & 2.22 & $>20$ & $>20$ \\
\hline $\mathrm{A} 10$ & $*^{\circ-0} \square-0^{\prime}$ & $*^{-\infty-1}$ & 1.50 & 1.13 & 0.66 \\
\hline A11 & $\gamma \supset=$ & i & 1.42 & $>20$ & 17.9 \\
\hline $\mathrm{A} 12$ & $.0-\square$ & $* 0-0$ & 7.80 & 1.73 & 0.96 \\
\hline A13 & $x^{H}-\langle\rangle^{0}$ & $+N^{H}-\square$ & 2.70 & $>20$ & $>20$ \\
\hline A14 & $x^{*}-\square_{0}^{2}$ & $x-\gamma_{0}^{2}$ & 0.30 & 1.2 & 0.98 \\
\hline
\end{tabular}

Figure 2. Structure-activity relationship of HIT-A derivatives. The $\mathrm{IC}_{50}(\mu \mathrm{M})$ values obtained in alpha-screen, HTRF and cell cytotoxic assays of 15 compounds in Ty 82 cells are summarized. HTRF assay was performed for the compounds which exhibited inhibitory activities in the alpha-screen assay. HTRF, homogeneous time-resolved fluorescence.

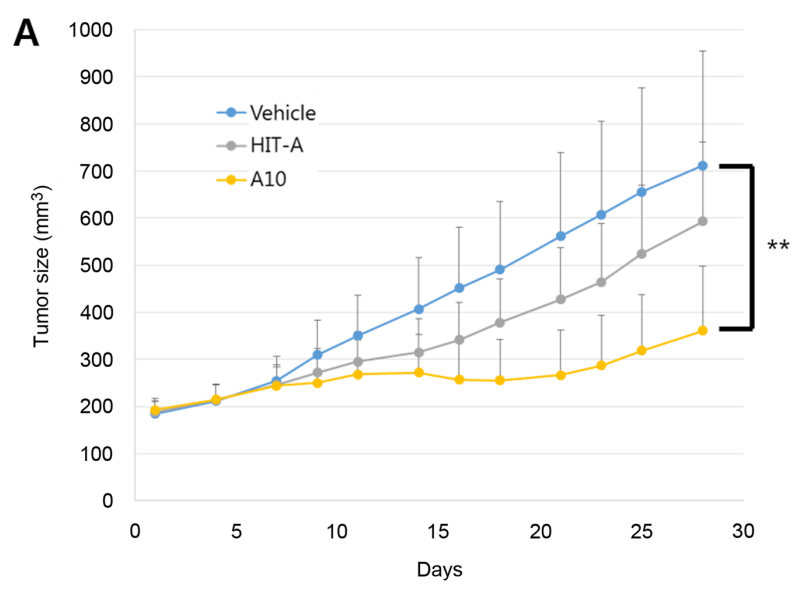

B

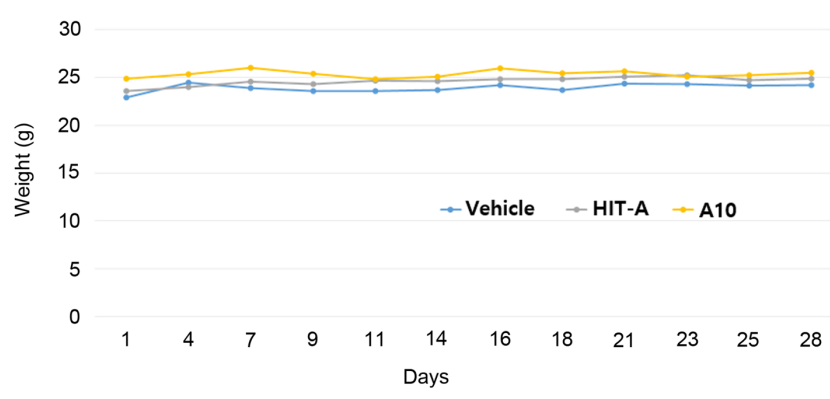

Figure 3. In vivo xenograft assay. Ty82 cells were implanted into nude mice and allowed to grow to $200 \mathrm{~mm}^{3}$. Vehicle or $100 \mathrm{mpk}$ bromodomain inhibitors were orally administered daily. (A) Tumor sizes were measured every 2-3 days throughout the treatment period using calipers. Results are presented as the mean \pm SEM. Statistical comparisons between Vehicle-treated and compound-treated groups were performed using two-way ANOVA with Dunnett's multiple comparisons test. ${ }^{* *} \mathrm{P} \leq 0.01(\mathrm{n}=6)$. (B) Body weights were measured every 2-3 days throughout the treatment period.

\section{Discussion}

Compound screening such as high-throughput or mid-throughput screening is a key step of the early stage in drug development, to identify molecules which have activity on specific targets. However, this step is easily weakened by a high incidence of false-positives, which are not active toward the biological target of interest, but active in an assay (12). False positives result from the compound interference in assay system (13). These compound interference can be produced solely by compounds themselves, such as fluorescent compounds, or by their interaction with biological components in assay system (14). One of the powerful method to solve this problem is to use orthogonal assay systems (15-17). Here, we setup 2 orthogonal assays for bromodomain inhibitor screening, alpha-screen and homogeneous time resolved fluorescence assay. In this study, alpha-screen was used as primary screening assay for MTS. We identified more than 70 hits in alpha-screen assay. Subsequently, HTRF assay revealed that HIT-A compound is a true hit among 70 hits. To confirm HIT- A is a true hit, we checked c-myc expression level after HIT-A treatment in Ty82 cell line. Jang et al (18) reported that c-myc promoter is regulated by brd4 protein. Yang et al (19) also reported that c-myc expression is clearly impaired by brd4 knockdown. JQ-1, the first brd4 inhibitor, has demonstrated significant downregulation of c-myc protein (9). Therefore, various brd4 inhibitors were confirmed to be true hits by showing suppression of c-myc expression in cancer cell lines (20-23). Western blot data shows that HIT-A compound downregulates c-myc expression in Ty82 cell line, which means that HIT-A is a true hit. With 16 derivatives of HIT-A, we performed both biochemical assays. Interestingly, O-linked compounds exert inhibition in both assay systems, 

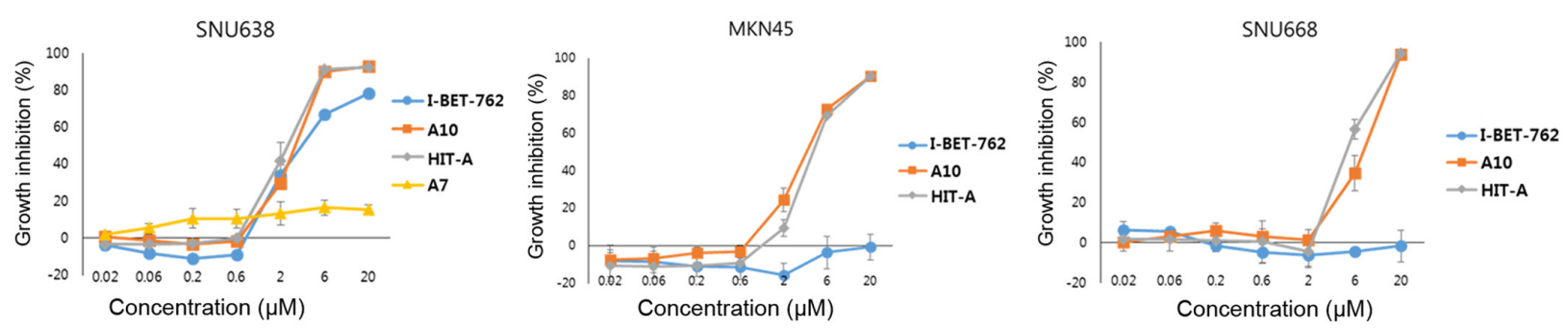

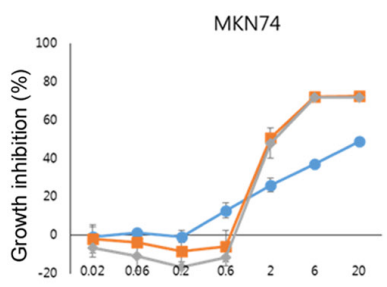

Concentration $(\mu \mathrm{M})$

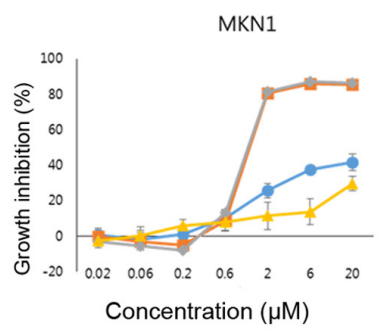

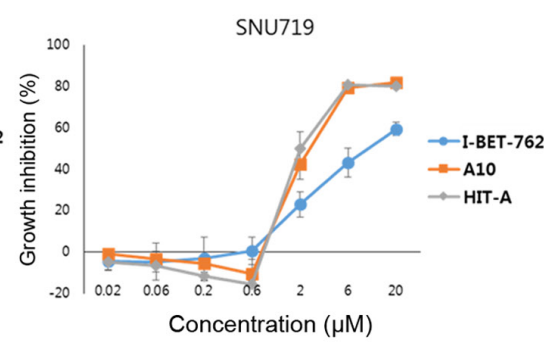
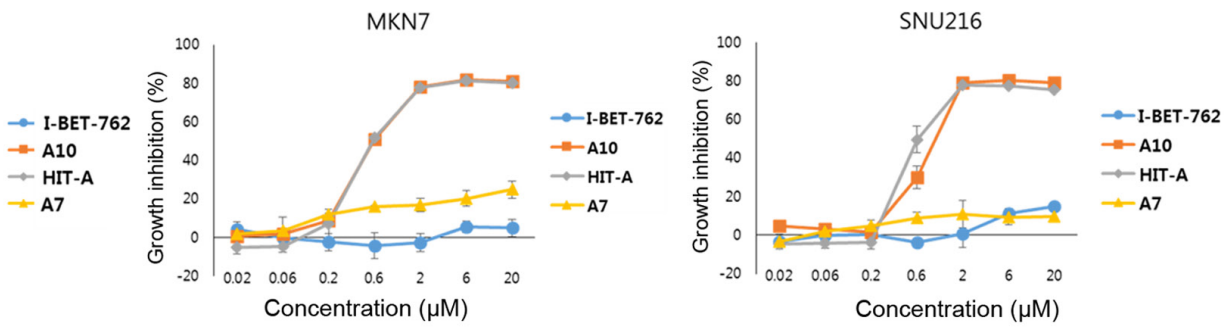

Figure 4. O-linked compounds, A10 and HIT-A, suppress the growth of gastric cancer cells. Bromodomain inhibitors were added to various gastric cancer cell lines, and cell proliferation was measured after $72 \mathrm{~h}$ using WST-1 agent $(\mathrm{n}=3)$.

A10

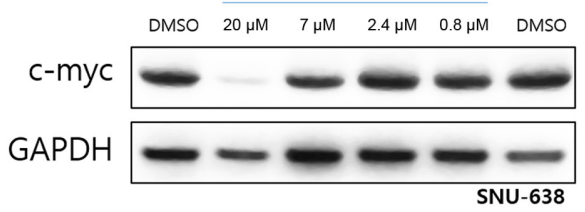

A10

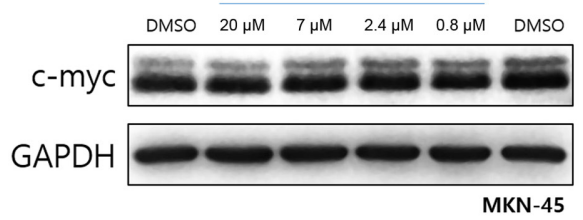

A10

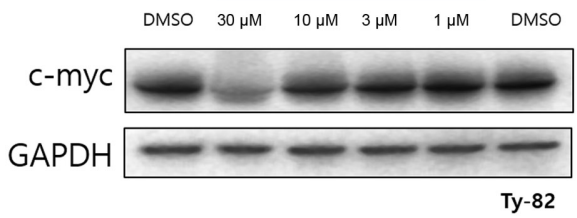

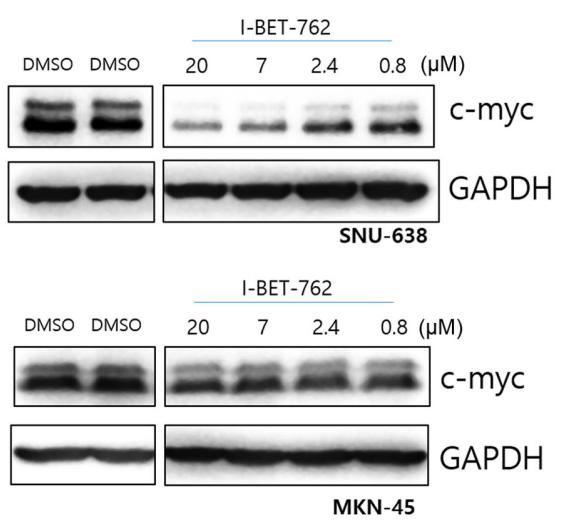

MKN-45

Figure 5. Downregulation of c-myc levels by bromodomain inhibitors. SNU-638, MKN-45 and Ty82 cells were treated with bromodomain inhibitors for 24 h, and c-myc levels were measured by western blotting.

however, non O-linked compounds exert inhibition only in alpha-screen. We anticipated that only O-linked compounds are real hit, because they exerted inhibition in both assay systems. As we expected, cell cytotoxic assay with Ty82, which is addicted to bromodomain activity, showed that only O-linked compounds exerted cytotoxicity in Ty82. This data reflects that our orthogonal assay system is very effective to remove false positives. In vivo assay, one of the hit derivatives, A10, showed excellent tumor growth inhibition without body weight change. We tested whether our hit compound is working on gastric cancer cells. O-linked compounds, A10 and HIT-A, shows cytotoxic effect against gastric cancer cells. Because 
A7, which didn't inhibit brd4 at all, exerted no cytotoxicity, it is sure that the cytotoxic effect of O-linked compound is due to the bromodomain inhibition. In addition, O-linked compounds showed cell growth inhibition even in I-BET-762-resistant cell lines, MKN45, SH-10-TC, SNU668, MKN7 and SNU216. Therefore, we anticipate that our compound is more powerful for cancer therapy than I-BET-762.

\section{Acknowledgements}

The chemical library used in the present study was kindly provided by Korea Chemical Bank (http://www.chembank. org/) of the Korea Research Institute of Chemical Technology (Daejeon, South Korea).

\section{Funding}

The present study was supported by the Korea Research Institute of Chemical Technology Research Fund (grant nos. SI1706 and SKO1706H01).

\section{Availability of data and materials}

The datasets used and/or analyzed during the current study are available from the corresponding author on reasonable request.

\section{Authors' contributions}

YHK and CHP confirm the authenticity of all the raw data. CHP developed this project. YHK performed the mid-throughput screening and found the HIT compound. JEK and MYY performed the enzyme assay to measure the inhibitory activities. MK performed the cell-based assay. HKL and COL performed and analyzed the in vivo experiment. KYJ and MJY synthesized the compounds. YK performed the cell-based assay. SUC analyzed the data. CHP designed the study, planned the experiments, analyzed the data and wrote the manuscript. All authors read and approved the final manuscript.

\section{Ethics approval and consent to participate}

Animal experiments were approved by the Laboratory Animal Care and Use Committee of Korea Research Institute of Chemical Technology (Daejeon, South Korea).

\section{Patient consent for publication}

Not applicable.

\section{Competing interests}

The authors declare that they have no competing interests.

\section{References}

1. Yang XJ and Seto E: Lysine acetylation: Codified crosstalk with other post-translational modifications. Mol Cell 31: 449-461, 2008.

2. Kouzarides T: Chromatin modifications and their function. Cell 128: 693-705, 2007.

3. Jenuwein $\mathrm{T}$ and Allis CD: Translating the histone code. Science 293: 1074-1080, 2001.
4. Sanchez R, Meslamani J and Zhou MM: The bromodomain: From epigenome reader to druggable target. Biochim Biophys Acta 1839: 676-685, 2014.

5. Tamkun JW, Deuring R, Scott MP, Kissinger M, Pattatucci AM, Kaufman TC and Kennison JA: brahma: A regulator of Drosophila homeotic genes structurally related to the yeast transcriptional activator SNF2/SWI2. Cell 68: 561-572, 1992.

6. French CA: NUT midline carcinoma. Cancer Genet Cytogenet 203: 16-20, 2010.

7. French CA, Ramirez CL, Kolmakova J, Hickman TT, Cameron MJ, Thyne ME, Kutok JL, Toretsky JA, Tadavarthy AK, Kees UR, et al: BRD-NUT oncoproteins: A family of closely related nuclear proteins that block epithelial differentiation and maintain the growth of carcinoma cells. Oncogene 27: 2237-2242, 2008.

8. Zuber J, Shi J, Wang E, Rappaport AR, Herrmann H, Sison EA, Magoon D, Qi J, Blatt K, Wunderlich M, et al: RNAi screen identifies Brd4 as a therapeutic target in acute myeloid leukaemia. Nature 478: 524-528, 2011.

9. Mertz JA, Conery AR, Bryant BM, Sandy P, Balasubramanian S, Mele DA, Bergeron L and Sims RJ III: Targeting MYC dependence in cancer by inhibiting BET bromodomains. Proc Natl Acad Sci USA 108: 16669-16674, 2011.

10. Brand M, Measures AR, Wilson BG, Cortopassi WA, AlexanderR, Höss M, Hewings DS, Rooney TP, Paton RS and Conway SJ: Small molecule inhibitors of bromodomain-acetyl-lysine interactions. ACS Chem Biol 10: 22-39, 2015.

11. French CA, Miyoshi I, Kubonishi I, Grier HE, Perez-Atayde AR and Fletcher JA: BRD4-NUT fusion oncogene: A novel mechanism in aggressive carcinoma. Cancer Res 63: 304-307, 2003.

12. Thorne N, Auld DS and Inglese J: Apparent activity in high-throughput screening: Origins of compound-dependent assay interference. Curr Opin Chem Biol 14: 315-324, 2010.

13. Simeonov A, Yasgar A, Klumpp C, Zheng W, Shafqat N, Oppermann U,Austin CP and Inglese J:Evaluation of micro-parallel liquid chromatography as a method for HTS-coupled actives verification. Assay Drug Dev Technol 5: 815-824, 2007.

14. Shapiro AB, Walkup GK and Keating TA: Correction for interference by test samples in high-throughput assays. J Biomol Screen 14: 1008-1016, 2009.

15. Weber E, Rothenaigner I, Brandner S, Hadian K and Schorpp K: A high-throughput screening strategy for development of RNF8-Ubc13 protein-protein interaction inhibitors. SLAS Discov 22: 316-323, 2017.

16. Carter DM, Specker E, Przygodda J, Neuenschwander M, von Kries JP, Heinemann U, Nazaré M and Gohlke U: Identification of a novel benzimidazole pyrazolone scaffold that inhibits KDM4 lysine demethylases and reduces proliferation of prostate cancer cells. SLAS Discov 22: 801-812, 2017.

17. Dahlin JL, Nissink JW, Strasser JM, Francis S, Higgins L, Zhou H, Zhang Z and Walters MA: PAINS in the assay: Chemical mechanisms of assay interference and promiscuous enzymatic inhibition observed during a sulfhydryl-scavenging HTS. J Med Chem 58: 2091-2113, 2015.

18. Jang MK, Mochizuki K, Zhou M, Jeong HS, Brady JN and Ozato K: The bromodomain protein Brd4 is a positive regulatory component of P-TEFb and stimulates RNA polymerase II-dependent transcription. Mol Cell 19: 523-534, 2005.

19. Yang Z, He N and Zhou Q: Brd4 recruits P-TEFb to chromosomes at late mitosis to promote G1 gene expression and cell cycle progression. Mol Cell Biol 28: 967-976, 2008.

20. Raux B, Voitovich Y, Derviaux C, Lugari A, Rebuffet E, Milhas S, Priet S, Roux T, Trinquet E, Guillemot JC, et al: Exploring selective inhibition of the first bromodomain of the human bromodomain and extra-terminal domain (BET) proteins. J Med Chem 59: 1634-1641, 2016.

21. Zhao L, Wang Y, Cao D, Chen T, Wang Q, Li Y, Xu Y, Zhang N, Wang X, Chen D, et al: Fragment-based drug discovery of 2-thiazolidinones as BRD4 inhibitors: 2. Structure-based optimization. J Med Chem 58: 1281-1297, 2015.

22. Tanaka M, Roberts JM, Seo HS, Souza A, Paulk J, Scott TG, DeAngelo SL, Dhe-Paganon S and Bradner JE: Design and characterization of bivalent BET inhibitors. Nat Chem Biol 12: 1089-1096, 2016.

23. Yang $\mathrm{Y}$, Fang L, Chen $\mathrm{P}$, Zhang $\mathrm{H}$ and Zhou J: Identification of 3,5-dimethylisoxazole derivatives as BRD4 inhibitors for the treatment of colorectal cancer. ACS Med Chem Lett 11: 2174-2181, 2020 .

This work is licensed under a Creative Commons Attribution-NonCommercial-NoDerivatives 4.0 International (CC BY-NC-ND 4.0) License. 